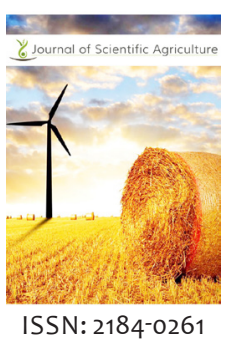

Received: June 24, 2020 Accepted: August 07, 2020 Published: August 13, 2020

*Corresponding Author: Md. Monirul Islam Email: mislambina73@gmail. com

\section{In vitro response and effect of gamma irradiation on four local indica rice varieties}

\author{
Md. Monirul Islam*, Md Taufiqur Rahman², Md. Hasanuzzaman², \\ Md. Shahidul Islam², Md. Imtiaz Uddin', Nihar Ranjan Saha² \\ 'Biotechnology Division, Bangladesh Institute of Nuclear Agriculture (BINA), BAU Campus, Mymensingh-2202, \\ ${ }^{2}$ Department of Biotechnology, Bangladesh Agricultural University, Mymensingh-2202
}

\begin{abstract}
In vitro response of four local Indica rice cultivars viz. Sadamota, Kachamota, Moulata and Dudhkalam was evaluated. The aim of this study is to develop an efficient protocol for callus induction, plant regeneration and to observe the effect of gamma radiation on plant regeneration for creating possible genetic variability. In Different concentration of 2,4-D and growth regulators were supplemented with MS medium (Murashige and Skoog's) to observe their callus induction frequency using mature embryo as explant. Among the cutivars, the highest primary callus (92.55\%) as well as embryogenic callus induction $\left(56.26 \%\right.$ ) was showed in sadamota at $3.0 \mathrm{mgl}^{-1} 2,4-\mathrm{D}$ and $10 \mathrm{mgl}^{-1}$ kinetin under dark condition. Twenty one days old embryogenic calli were exposed to 0,2, 4 and 6 Gy of gamma rays and transferred to regeneration medium. Both callus growth and regeneration capacity were found to be decreased with increasing level of exposure to gamma rays. The doses of $4 \mathrm{~Gy}$ of gamma radiation were found to be the $50 \%$ inhibition dose for callus growth and plant regeneration in sadamota and kachamota, repectively whereas the $50 \%$ inhibition dose for moulata and dudhkalam at $2 \mathrm{~Gy}$. This results indicate that sentivity of gamma radiation on rice callus depends on genotype of a genus.
\end{abstract}

KEYWORDS: Indica rice, gamma radiation, callus growth, plant regeneration

\section{INTRODUCTION}

Rice (Oryza sativa L.) is one of the most important cereal crops, which supplies food for more than half of the world population [1]. In the coming 30 years, the world will require $70 \%$ more rice than that it requires today. According to conservative estimates, 800 million tons of rice will have to grown with considerable reduction in the input of agrochemical under sustainable conditions [2]. In Bangladesh, rice is the most dominant and main food crop, which grows in all the three crop growing seasons of the year [3].

The southern coastal belt of Bangladesh (about 2.0 m.ha) i. e the greater Barisal region is crisscrossed with innumerable rivers, rivulets, creeks and canals. Lands along these rivers are subject to inundation due to cyclic tidal flooding. Monsoonal tidal flooding and consequential inundation of land and often submergence of crop is the major problem of growing rice. Soil submergence and frequent crop inundation due to high tides twice daily over a period of 4-8 months (April-November) is the characteristic feature of tidal floodplain ecosystem. About $80 \%$ of the cultivable land of greater Barisal and Patuakhali districts is inundated up to a range of 6-90 $\mathrm{cm}$ during monsoon presenting difficulty in growing modern varieties of transplanted T. aman rice. Farmers use tall statured, photosensitive, long duration, traditional cultivars tolerant to tidal flooding. A few cultivars namely Sadamota, Moulata, Lalmota and Dudkalom dominate for cultivation in T. aman cropping season in these areas [4]. Having endured the climatic variability and environmental hazards, these cultivars are being grown in the region over ages. However, the yield of the traditional varieties is low $(<2.0 \mathrm{t} / \mathrm{ha})$ and also long duration (>170 days). Therefore, agricultural scientists to develop varieties which are capable to produce more yield both in submerged and flood tide conditions. But the traditional methods of rice breeding are not sufficient enough to meet the demand of developing rice varieties in the shortest possible time in twenty first century. Many researchers have attempted to exploit many options for rice varieties development out of this induced mutagenesis on embryogenic calli by treatment with low gamma radiation serves as a better source of variability $[5,6,7]$. The variability in the population leads the chance of effective selection and increases the scope of improvement [8]. Considerable works have been done on induced mutation in rice callus by many workers $[8,9,10]$ applied low doses of gamma ray treatments to rice callus and found

Copyright: ๑ The authors. This article is open access and licensed under the terms of the Creative Commons Attribution License (http://creativecommons.org/licenses/by/4.0/) which permits unrestricted, use, distribution and reproduction in any medium, or format for any purpose, even commercially provided the work is properly cited. Attribution - You must give appropriate credit, provide a link to the license, and indicate if changes were made. 
significant effect on callus induction. Considering the background information, the present study was undertaken to investigate the extent of variability on callus production and plant regeneration at different doses of gamma radiation of four local rice cultivars.

\section{MATERIALS AND METHODS}

The experiment was conducted during the period of January 2018 to November 2018 at the Tissue Culture Laboratory of Biotechnology Division, Bangladesh Institute of Nuclear Agriculture (BINA), Mymensingh, Bangladesh. Four local Indica rice cultivars viz., Sadamota, Moulata, Dudkalam and Kachamota were used in this study. The materials used in the experiment were obtained from larger Barisal region by the courtesy of Biotechnology Division, Bangladesh Institute of Nuclear Agriculture (BINA). Mature rice embryos were used as explants for callus initiation and subsequent plant regeneration.

The dehusked seeds were then washed five times with autoclaved distilled water. Then one minute washed with $70 \%$ ethanol. After then it washed three times with autoclaved distilled water. The floating dehusked seeds were discarded. The surface sterilization of these dehusked seeds was carried out in the aseptic conditions of a laminar air flow cabinet. The seeds were taken into a sterile tube and immersed into $3.5 \% \mathrm{NaOCl}$ with 2 drops of Tween twenty solution for 15 minutes with shaking followed by 10 times rinsed in autoclaved distilled water to remove traces of $\mathrm{NaOCl}$ and Tween twenty. After that seeds were dried about 5 minutes and sterilized seeds were cultured in MS medium with $3 \mathrm{mg} / \mathrm{l}$ 2,4-D and $10 \mathrm{mg} / \mathrm{K} \mathrm{K}$ growth regulator combination, $30 \mathrm{~g} / \mathrm{l}$ sucrose and $5.6 \%$ gelrite to initiate callus and incubated under dark condition.

Calli of twenty-one-day old were subjected to 4 different doses $(0,2,3,5$, and $6 \mathrm{~Gy})$ of gamma rays from $60 \mathrm{Co}$ source. About 50-65 calli were exposed to each radiation level. Irradiated calli were transferred to MS medium supplemented with $0.5 \mathrm{mg} / \mathrm{l}$ $\mathrm{NAA}$ and $10 \mathrm{mg} / \mathrm{l} \mathrm{Kn}$ fo. Repeated sub-culturing was done at 15 days interval for callus proliferation and organogenesis in same regeneration medium. Those irradiated calli continued to be proliferated and differentiated into shoots. When these shoots grew to about $3-4 \mathrm{~cm}$ height, these were separated aseptically from each other and transferred to freshly prepared rooting medium (half strength $\mathrm{MS}+0.5 \mathrm{mg} / \mathrm{l} \mathrm{IBA}$ ) and kept in growth room at $25 \pm 2^{\circ} \mathrm{C}$. Data were recorded on survival rate, plant regeneration and number of regenerated shoots per callus. The collected data were analysed statistically as completely randomized design following the analysis of variance (ANOVA) technique and the mean differences were adjusted with Duncan's Multiple Range Test (DMRT) using the statistical computer package programme, MSTAT-C.

\section{RESULTS AND DISCUSSION}

The mature embryos of four local rice cultivars were inoculated on various treatments to observe the callus formation response. Callus formation invariably developed within 21 days. Among the cultivars, high average callus initiation (\%) was observed in Sadamota (92.55\%) followed by Kachamota (91.96\%).Initiation of embryogenic calli in rice is considered most critical step. It also appeared that Kachamota and Sadamota had better callus initiation efficiency in comparison to Moulata and Dudhkalam.

The result was indicated that gamma radiation had inverse effects on survival rate, plant regeneration and number of regenerated shoots per callus (Table 1).

It was clearly observed that survivability of twenty one days irradiated calli varied on different range of gamma radiation. Survival rate of callus varied from $81 \%$ to $21 \%$. In all cases, The growth regeneration capability of calli were found to be higher in control than in the irradiated calli. Plant regeneration percentage was ranged from $0 \%-33.53 \%$ in Moulata, $48.86 \%$ to $20.73 \%$ in Sadamota, in Dudhkalam $44.03 \%$ to $15.73 \%$ in Kachamota $0 \%$ to $30 \%$. Increasing the doses of gamma radiation decreased the shoot regeneration capacity. The calli could be viable in Shadamota and Kachamota by $50 \%$ at $6 \mathrm{~Gy}$ of radiation, whereas, in Moulata and Dudhkalam, was reduced to $50 \%$ at 4 Gy of radiation.

The percentage of plant regeneration decreases from $48.86 \%$ to $0 \%$ while number of regenerated shoots callus ranged from $5.6 \%$ to $0 \%$. A few numbers of shoots were produced from the Sadamota irradiated with 4 Gy as compared to control. Both growth and regeneration capacity decreased with increasing levels of gamma rays; however, plant regeneration capacity was more sensitive to gamma rays than growth $[5,11]$. observed that 2.5-5.0 Gy is the optimal dose range for mature embryos of rice.

In vitro regeneration of both control and irradiated (4 Gy) calli from mature embryo of Sadamota are shown in Figure 1.

Similar findings have been reported earlier by many workers $[12,5,6,7]$. However, the $50 \%$ inhibition dose (LD50)

Table 1: Survival rate, plant regeneration and number of regenerated shoots per callus of irradiated calli developed from indica rice

\begin{tabular}{lcccc}
\hline Survival rate \% & $\begin{array}{c}0 \text { Gy } \\
\text { (Control) }\end{array}$ & 2 Gy & 4 Gy & 6 Gy \\
\hline Moulata & $71.36^{\mathrm{bc}}$ & $67.00^{\mathrm{c}}$ & $53.00^{\mathrm{c}}$ & $23.46^{\mathrm{c}}$ \\
Sadamota & $81.00^{\mathrm{a}}$ & $76.93^{\mathrm{a}}$ & $72.43^{\mathrm{a}}$ & $48.00^{\mathrm{a}}$ \\
Dudhkalam & $69.00^{\mathrm{c}}$ & $66.50^{\mathrm{c}}$ & $49.93^{\mathrm{c}}$ & $21.00^{\mathrm{c}}$ \\
Kachamota & $77.50^{\mathrm{ab}}$ & $72.06^{\mathrm{b}}$ & $62.63^{\mathrm{b}}$ & $37.00^{\mathrm{b}}$ \\
Level of sig. & $* *$ & $* *$ & $* *$ & $* *$ \\
Regeneration\% & & & & \\
$\quad$ Moulata & $33.53^{\mathrm{b}}$ & $26.46^{\mathrm{b}}$ & $15.00^{\mathrm{c}}$ & $0.000^{\mathrm{c}}$ \\
$\quad$ Sadamota & $48.86^{\mathrm{a}}$ & $41.10^{\mathrm{a}}$ & $33.00^{\mathrm{a}}$ & $20.73^{\mathrm{a}}$ \\
$\quad$ Dudhkalam & $30.00^{\mathrm{b}}$ & $18.00^{\mathrm{c}}$ & $7.200^{\mathrm{d}}$ & $0.000^{\mathrm{c}}$ \\
Kachamota & $44.03^{\mathrm{a}}$ & $39.00^{\mathrm{a}}$ & $27.83^{\mathrm{b}}$ & $15.73^{\mathrm{b}}$ \\
$\quad$ Level of sig. & $* *$ & $* *$ & $* *$ & $* *$ \\
Shoot/callus & & & & \\
$\quad$ Moulata & 5.00 & $5.33^{\mathrm{a}}$ & $2.26^{\mathrm{bc}}$ & $0.00^{\mathrm{c}}$ \\
$\quad$ Sadamota & 5.60 & $5.10^{\mathrm{b}}$ & $4.46^{\mathrm{a}}$ & $3.10^{\mathrm{a}}$ \\
$\quad$ Dudhkalam & 4.53 & $4.10^{\mathrm{c}}$ & $1.46^{\mathrm{c}}$ & $0.00^{\mathrm{c}}$ \\
Kachamota & 5.80 & $1.73^{\mathrm{d}}$ & $2.53^{\mathrm{b}}$ & $1.33^{\mathrm{b}}$ \\
Level of sig. & $\mathrm{NS}$ & $* *$ & $* *$ & $* *$ \\
\hline
\end{tabular}

In a column, within treatment, figure(s) having the same letter(s) do not differ significantly as per DMRT at P $\leq 0.05 ; * *$ Significant at $1 \%$ level of probability; NS- not significant 


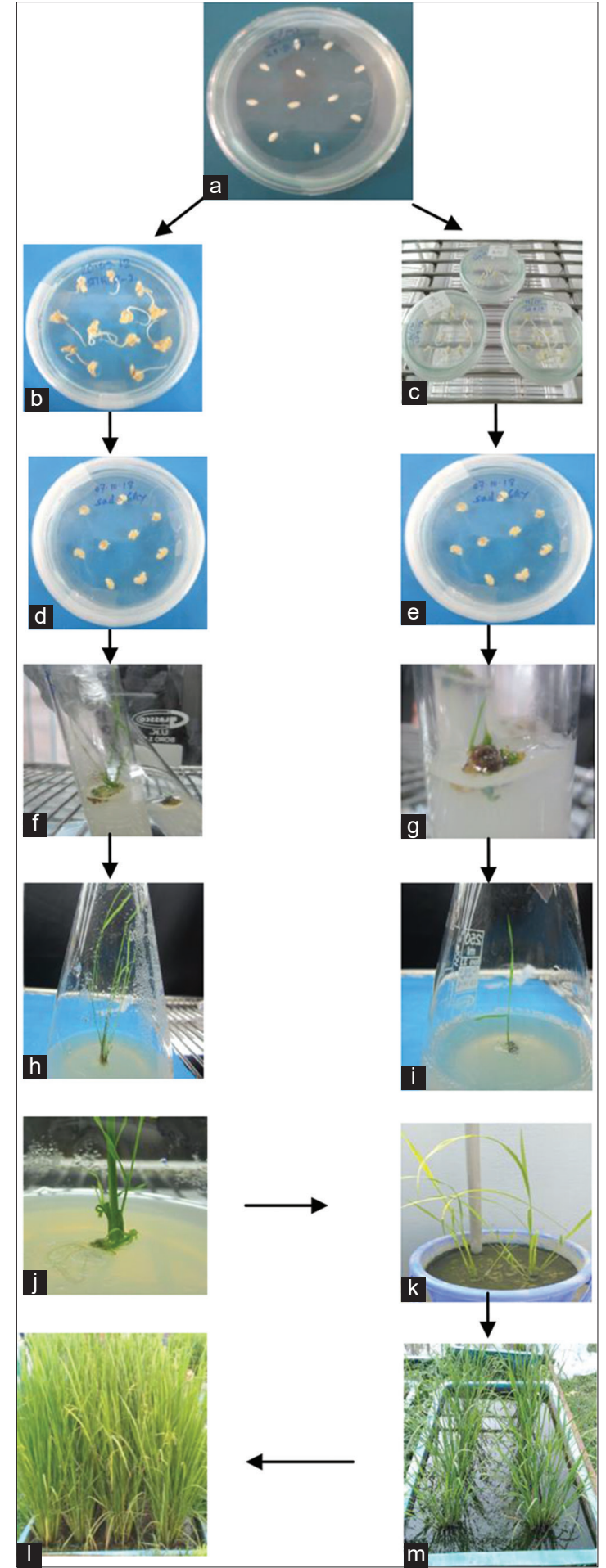

Figure 1: In vitro regeneration from mature embryo of irradiated embryogenic callus of rice cultivars Sadamota(a-m). Schematic representation of mature embryo culture on callusing medium (a), 21days old Embryogenic Calli (b), 21days old Irradiated Embryogenic Calli (c), 21 days Sub-cultured Embryogenic Calli on shooting Medium (d), 21 days Irradiated Calli Sub-culture on shooting Medium (e), established selected calli on shooting medim (f), Irradiated established selected calli on shooting media (g), Shoot regenerated from non-irradated embryo $(\mathrm{h})$, Shoot regenerated from non-irradated embryo (i), regenerated plant transferred on rooting media (j), Established Regenerated plants in pot $(\mathrm{k})$, then the mature plants established on soil (I), finally regenerated plants was flowering $(\mathrm{m})$ for plant regeneration, 4 Gy of gamma radiation would be upper limit in the, sadamota and Kachamot whereas 2 Gy would be for remaining varieties.

DNA damages and mutation in Chromosmes caused by irradiation may be responsible for slow growth and reduction in regeneration rate. It was mentioned that the growth and regeneration abilty of irradiated calli was negatively affected with an increasing the level of gamma doses. Moreover, these results indicate that sensitivity of gamma radiation depend on genotypes of a genus.

The results of this study revealed that $6 \mathrm{~Gy}$ of gamma ray might be considered as LD50 for sadamota and Kachamota. The LD50 for Moulata and Dudhkalam were found to be 4 Gy as these varieties showed $50 \%$ survivability after irradiation of calli.

\section{CONCLUSIONS}

The results of this study revealed that 6 Gy of gamma ray might be considered as LD50 for sadamota and Kachamota. The LD50 for Moulata and Dudhkalam were found to be 4 Gy as these varieties showed $50 \%$ survivability after irradiation of calli.

\section{ACKNOWLEDGEMENTS}

We are thankful to the Ministry of Agriculture, the Peoples Republic of Bangladesh, for financial support.

\section{REFERENCES}

1. Tyagi AK, Khurana JP, Khurana P, Raghuvanshi S, Gaur A, Kapur A, Gupta V, Kumar D, Ravi V, Vij S, Khurana P Sharma S Structural and functional analysis of rice genome. Journal of Genetics 2004 83:79-99.

2. IRRI Annual report of International Rice Research Institute. IRRI. Loss Banos, Philippines. 2004.

3. Waddington SR, E-Elahi N and Khatun F () The Expansion of Ricemaize Systems in Bangladesh. Invited Oral Presentation in the Symposium on Emerging 2006

4. Shamsuzzaman, KM and Haque, MM Performance of modern varieties of transplanted aman rice and mungbean in selected locations in tidal floodplain, pp. 26-30. In Crop Production in the Coastal Ecosystem-Challenges and Opportunities. Agrarian Research Foundation, Dhaka, 2010.

5. Hossain MF and Alam MS. Effect of Gamma Irradiation on the Callus, Developed from Indica Rice. Pakistan Journal of Biological Science. 2001;4: 670-671.

6. Hasabullah NA, Taha RM, Saleh A, Mahmad N Irradiation effect on in vitro organogenesis, callus growth and plantlet development of Gerbera jamesonii. Horticultura Brasileira 2012;30: 252-257.

7. Puteh, Adam B, Mondal MMA (2014) Effect og gamma radiation on indica rice callus of landraces and modern varieties. Journal of food, Agric. \& Envir. vol.12 (12): 290-291

8. Hossain MF, Samad MA and Alam NS. Effect of gamma irradiation on rice callus. Bangladesh J. Nuclear Agric. 2008;24:133-135.

9. Chen QF, Wang CL, Lu YM, Shen M, Afza R, Duren MV, Brunner H. Anther culture in connection with induced mutations for rice improvement. Euphyt. 2001;120:401-408.

10. Min S, Xian Z, Qi X and Zhao C. Effects of gamma-ray radiation treatment on somatic cell culture in rice. Cereal Res. Comm. 1991 2:201-208

11. Gao MW, Cai $\mathrm{OH}$ Liang ZQ. In vitro culture of hybrid indica rice combined with mutagenesis. Plant Breeding 1992;108:104-110.

12. Venkateshwarlu M. Effect of gamma rays on different shoots in Cucumis melo cv. Bathusa. Journal of Environmental Biology. 2008;29:789-792. 